\title{
Persuasive Papers, Speeches, and Campaigns ${ }^{1}$
}

\author{
Laura Gorham, Ricky Telg, and Tracy Irani²
}

\section{Introduction}

Persuasion is a communication technique that attempts to influence or convince others to take action or to reach a specific conclusion about an issue. Persuasion can be used in written essays, speeches or as part of media campaigns that attempt to influence an audience to change their thinking or behavior. This publication will familiarize you with the tools necessary to develop a persuasive essay, speech, or media campaign.

\section{Preparing Your Persuasive Paper or Speech}

When writing a persuasive paper or preparing for a persuasive speech, you should begin by focusing on the main issue or problem that people disagree about. Try to separate personal judgements and emotions from your argument. The most effective persuasive argument appeals to reason, not emotion.

Persuasive arguments should have a simple structure, and begin by directly stating what is good or bad, and why you think so.

One way to structure a persuasive argument in written or spoken form is to use the five-part argument, which breaks an essay or speech into 1) introduction, 2) background, 3) lines of argument, 4) refuting objections, and 5) conclusion.

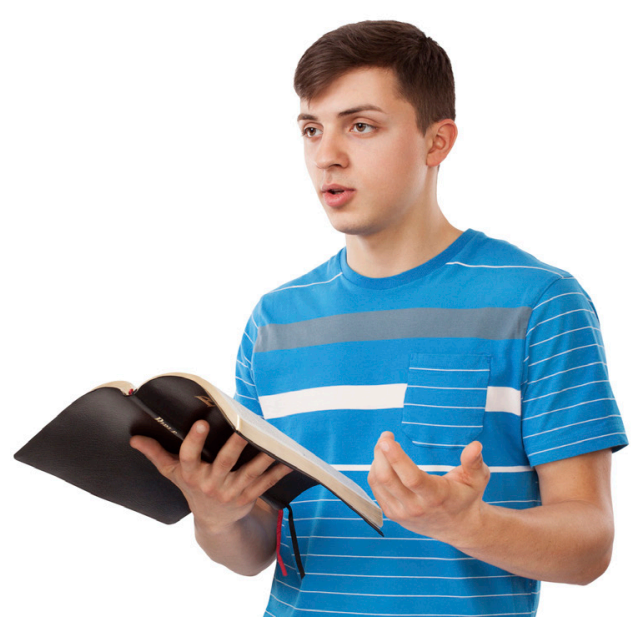

\section{Introduction}

The introduction attracts the attention of the audience, sets the tone and describes what the argument will be about. The introduction usually includes the thesis statement, a sentence that explains what the main point of the argument will be.

\section{Background}

The background provides the context and details needed for a reader or listener to understand the situation being described, as well as the problem or opportunity being addressed.

\section{Lines of Argument}

Lines of argument make up the body of the essay or speech. Here is where you include all the claims, reasons, and

1. This document is AEC483 (formerly WC146), one of a series of the Agricultural Education and Communication Department, UF/IFAS Extension. Original publication date July 2013. Visit the EDIS website at http://edis.ifas.ufl.edu.

2. Laura Gorham, graduate student; Ricky Telg, professor; and Tracy Irani, professor, Agricultural Education and Communication Department, UF/IFAS Extension, Gainesville, FL 32611. 
supporting evidence you have that help you make your points effectively.

\section{Refuting Objections}

Refuting objections is an often-overlooked part of an effective persuasive argument. "Refuting" means disproving, ruling out, and countering any potential objections before the readers or listeners can think of reasons not to be persuaded

\section{Conclusion}

The conclusion is where you present your closing arguments. To be effective, the conclusion should restate your thesis statement and summarize the main points of your argument. If you are advocating a particular solution to a problem or a decision to be made, you should close by asking your reader or listeners to adopt your point of view.

\section{Informational and Educational}

\section{Campaigns}

A communications campaign is a strategic, structured plan consisting of a mix of media and message strategies with a consistent, unified theme. Communications campaigns analyze the client, competitors, the potential target audience, and the media mix as a prelude to developing the plan. Campaigns can promote ideas or products, or provide information and education. In this section, informational campaigns and educational campaigns will be highlighted.

An informational campaign is a special type of communications campaign in which one of your chief goals is to communicate information, using appropriate tools packaged for specifically targeted audiences and strategically framed messages, which is sometimes called a "message strategy." An example of an informational campaign might be informing people about Extension activities or programs available in your region. The purpose of an informational campaign is just to provide information, not necessarily to change a person's attitudes or behavior.

In an educational campaign, the goal is usually to communicate information, but with the added purpose of educating a targeted audience. The result of an educational campaign would be a change in attitude or behavior. $A$ social marketing campaign is a special type of educational campaign that uses persuasion, communicated via the media or interpersonally through individuals or organizations, to educate and inform audiences to engage in socially desirable behaviors, such as conserving water or improving one's health and fitness. While most educational campaigns are aimed at raising awareness and knowledge levels, social marketing campaigns focus on trying to change people's behavior. A strategic effort aimed at school children to teach them how to recycle in their homes, resulting in a change in behavior - such as having the children provide some indication of how their families recycle following the educational campaign - would be an example of a social marketing educational campaign.

\section{Planning an Informational or Educational Campaign}

Informational and educational campaigns use a combination of communication techniques, ranging from interpersonal to mass communication, and they typically start by developing a plan that identifies the problem and provides background and rationale for the campaign. The elements of the campaign are next developed, then presented either to internal or external decision-makers, and then implemented. An evaluation method of some type is usually suggested as a way to determine or evaluate the success of the methods used in the campaign.

\section{Campaign Elements}

An informational or educational campaign's plan will consist of goals and objectives, strategies, rationale, tactics, and evaluation.

\section{GOALS AND OBJECTIVES}

The goal is the overall purpose of the campaign. For example, who will benefit from the campaign and why? What are the potential outcomes, should this plan be implemented?

An objective is more specific than a goal. It provides clear guidance that permits the orderly presentation of content leading to some effect in the identified audience.

Here is an example of how goals and objectives could be developed for a campaign to provide information to restrict the spread of pro-anorexia websites:

- Goal: Pass legislation restricting underage admittance onto pro-anorexia websites.

- Objective: Increase by $20 \%$ awareness among high school students and their parents about the potential harm caused by unrestricted access to websites promoting anorexia.

\section{STRATEGIES}

Strategies are statements as to how tactics will be employed to achieve the stated objectives and goals. Strategies are decisions based on what you know of communication 
processes, your target audience, and other situations that have similar aspects that you can draw on to fit your current circumstances. Strategic decisions indicate how you will target your audience and the rationale for doing so. Some strategies to consider implementing include:

- Develop a strategy for the type of mass media communications you plan to use, such as print, television, radio, and billboards.

- Develop a message strategy of how you will frame the information or education message.

- Develop a strategy for the non-mass-media communications you plan to use, such as special events, public relations, or speakers.

\section{RATIONALE}

Rationale means to draw on what you know of communication processes and explain why this package of strategies is the best possible way to achieve your objectives and goals.

\section{TACTICS}

Tactics are specific elements that you will use in your campaign, such as a news release or a print advertisement. Identify a set of tactics you plan to use. Make sure you describe what each tactic is and what message or information it will contain. Following is a partial listing of some specific communications-oriented elements you might use for information/education campaigns:

- Brochures

- Print advertisements

- Radio and television commercials

- Posters

- Billboards

- Fliers

In addition to the above tactics that you might use in your campaigns to communicate to a mass audience, do not forget these more educationally-oriented tactics for an educational campaign:

- Lesson plans

- Curriculum guides

- Computer slide presentations

- Videos

- Websites

- Newsletters

- Training programs
- Books

- CD-ROMs and DVDs

\section{EVALUATION}

Evaluation consists of those ways in which you can gauge the effectiveness of your campaign. Typically, evaluation consists of measuring tangibles, such as the numbers of audience members reached, the number of times the campaign was mentioned in the news media, the number of brochures or other elements produced and disseminated, or the number of hits on the website. Evaluation can also consist of measuring intangibles, such as assessing the opinions formed, changed behavior or knowledge gained by your audience as a result of the campaign. Intangibles are measured through surveys, questionnaires, and focus groups. Some questions you may want to consider in your evaluation include:

- Did your audience become more aware of the issue or problem?

- Did the audience come to understand the issue or problem more fully?

- Did the audience members' attitudes change?

- Did audience members decide to adopt a new behavior or change an existing behavior?

\section{Summary}

The art of persuasion is as old as human society itself, and the rules have changed little over the years. In order to persuade people effectively, be it in speech, writing, or multimedia campaigns, it helps to present a convincing argument. Good arguments are tightly structured, clearly spoken, and designed to appeal to your audience. By practicing and following some of the guidelines outlined above, you may even surprise yourself with the power of persuasion.

\section{Reference}

Telg, R.W. \& Irani, T.A. (2012). Agricultural communications in action: A hands-on approach. Delmar Cengage Learning: Clifton Park, NY. 